\title{
Could Regional and Cantonal Banks Reduce Credit Risk through National Diversification?
}

\author{
Bertrand Rime*
}

JEL Classification: G21, G28, G31

Key words: diversification, economic capital, consolidation

\section{Introduction}

In this paper, we estimate the credit risk reduction potential implied by a national diversification of bank lending in Switzerland.

The Swiss bank loan market is characterized by the co-existence between a small number of large banks operating at the national level - the big banks and a few commercial banks - and about 120 smaller banks operating at the regional or cantonal level - the cantonal and the regional banks. Besides, there is the hybrid model of the Federation of Raiffeisen banks: each member bank operates at the regional level, but the Federation covers the whole country and there is an extended solidarity mechanism between member banks.

Remarkably, the allocation of market shares between banks operating at the national level and those operating at the regional level has remained quite stable since the beginning of the 1990's. The national "business model" represents about $40 \%$ of the volume of domestic lending, while the local and hybrid models represent about $50 \%$ and $10 \%$ respectively. ${ }^{1}$

The traditional explanation for the co-existence between the national and the regional business models lies in a possible trade-off between the costs and benefits of risk diversification. ${ }^{2}$ The diversification of the loan portfolio will be costly

* Financial Stability Section, Swiss National Bank, P.O. Box, 8022 Zurich, Switzerland. The views in this paper do not necessarily reflect those of the Swiss National Bank. The author thanks Robert Bichsel, Swiss National Bank, the editor and an anonymous referee of this journal for their constructive comments.

1 Source: Swiss National Bank (2006).

2 Acharya, Hasan and Saunders (2002), for example, argue that a bank's monitoring effectiveness may be lower in newly entered markets. But their empirical findings on the effects of 
if entering a local loan market implies some fixed cost: for example, screening local borrowers and assessing local business conditions may require the creation of a branch. In that case, the competitive pressure on lending interest rates from banks operating at the national level will be limited by the fact that their advantage in terms of risk diversification is partially compensated by the cost of entering several local markets.

With the development of credit risk models, however, the trade-off between the costs and the benefits of diversification has become less evident. Using computer-based credit scoring techniques, banks can assess the risk profile of potential borrowers "at a distance", i.e. without having recourse to the more qualitative judgement of the local credit manager (LeYshon and Thrift, 1999). This can substantially reduce the cost of entering local markets and, thereby, the cost of national diversification. ${ }^{3}$ Under the assumption that the cost of entering local markets has decreased, the competitive pressure from banks using the national business model should become stronger and bring lending rates down to a level where the local component of credit risk is not remunerated anymore. As a consequence, banks operating at the local level might face difficulties in remunerating and thus maintaining the level of economic capital necessary to cover the local component of credit risk. Eventually, the erosion of local banks' capital base could result in a higher risk of default in this bank category.

Of course, the mechanism described above matters only if the local component of credit risk is material, i.e., if a national diversification of the loan portfolio leads to a substantial reduction of credit risk. The quantification of this diversification potential is the object of the present study. In a first step, we develop a credit risk model where the evolution of the cantonal (i.e., regional) corporate default rates depend on various macroeconomic variables reflecting the national and cantonal business cycles. In a second step, we calculate the credit risk for a national loan portfolio and for portfolios consisting of the same number of loans in each canton. In a third step, we calculate the credit risk diversification potential as the difference between (i) the average of the risks of the cantonal portfolios and (ii) the risk of the national portfolio.

geographic diversification contradict this hypothesis. For a theoretical analysis of the tradeoff between the benefits and costs of diversification, see HeLlWIG (1998).

3 From 1998 to 2003, a period that broadly coincides with the introduction of credit risk models, the two Swiss big banks reduced the number of their branches by $26 \%$ (of which about $3 \%$ were directly related to the UBS-SBC merger), while the number of branches at cantonal and regional banks remained stable. 
Depending on the credit risk indicator - value at risk and expected shortfall at the $1 \%$ level - and on the size of the loan portfolio, we find a risk diversification potential representing 10 to $20 \%$ of the average of the risks of the cantonal portfolios. Assuming that there is no other source of risk, the indicators mentioned above represent the amount of economic capital that a bank needs to achieve a $1 \%$ default probability. Hence, our estimates of the credit risk diversification potential imply that a bank operating at the national level would be able to achieve the same $1 \%$ target default probability with about 10 to $20 \%$ less economic capital than a bank operating at the cantonal level. From a financial stability perspective, this finding should motivate particular scrutiny on the capital adequacy and profitability of the more than hundred Swiss banks that are staying on the regional business model.

The rest of the paper is organized as follows. Section 2 provides an overview on the methodology. In section 3, we model the relationship between the default rate and the economic environment. In section 4 and 5, we simulate default rate scenarios as well as the corresponding value distributions of the national and cantonal portfolios. Section 6 presents the estimates of the risk diversification potential. Section 7 provides a robustness check based on provisioning. Section 8 concludes.

\section{Overview on the Methodology}

The model used in this paper is inspired from Mc Kinsey's CreditPortfolioView (see Wilson 1997a and 1997b). We model the cantonal default rates as a function of several systematic risk factors - measuring macroeconomic conditions at the national and the cantonal level. This approach has two advantages over traditional credit risk models. First, it provides credit risk estimates for the loan portfolio that are conditional on the state of the economy. Thereby, it accounts for the empirical observation that corporate default rates are subject to substantial fluctuations throughout the business cycle. Over the period 1979-2000, the coefficient of variation of the national corporate default rate at the national level was $30 \%$. And the variations of the corporate default rate were negatively correlated with economic activity (see Table 1). Empirical evidence for other countries also supports the idea that the number of defaults - and downgrades - is larger during a recession than in an expansion. ${ }^{4}$ Second, this approach enables us to

4 See Nickell, Perraudin and Varotto (2000), Ervin and Wilde (2001), Carey, 2002, Bangia, Diebold, Kronimus, Schagen and Schuermann (2002), and Pesaran, SchuerMANN, TReutLer and Weiner (2006). 
model the interdependencies between the cantonal default rates in a flexible way. In particular, we can account for the fact that these interdependencies depend on multiple factors and that they can vary over time. By contrast, most traditional credit risk models usually rely on unconditional default rates, representing 10 or 20 years averages, and they capture the default interdependencies by relying on a single risk factor, or equivalently, by assuming a constant correlation. ${ }^{5}$

Table 1: Correlation between GDP Growth, Corporate Defaults and Provisioning

\begin{tabular}{lcc}
\hline & $1987-2000$ & $1979-2000$ \\
\hline corporate default rate & -0.65 & -0.33 \\
provisioning rate & -0.70 & -0.40 \\
\hline
\end{tabular}

In short, the estimation of the credit risk of the national and cantonal loan portfolios and of the corresponding diversification potential involves the following steps:

- We first estimate the historical relationship between the default rate and the economic environment for the different cantons;

- Based on these historical relationships, we simulate different scenarios regarding the state of the economy and we calculate the corresponding default rate scenario for each canton;

- Conditional on each default rate scenario, we simulate individual scenarios for each borrower in each canton. Thereby, we obtain the individual loan value distributions covering all the combinations between default rate scenarios and individual scenarios;

- By aggregating the loan value distributions over all borrowers in each canton (and over all cantons), we obtain the value distribution for each cantonal portfolio (and for the national portfolio);

- The value distributions of the national and cantonal portfolios are then used to compute the various risk indicators and the credit risk diversification potential.

5 For surveys on the various credit risk models, see SAUnders (1999), Crouni, Galai and Mark (2000), and Allen and Saunders (2004). 
We consider two indicators of credit risk: the value at risk (VaR) and the expected shortfall (ES). The VaR at the $\alpha \%$ level measures the maximum potential loss that the portfolio can suffer in the $99 \%$ best cases on a given time horizon. The $\mathrm{VaR}$ does not rely on a specific profit/loss distribution. However, an important drawback of the $\mathrm{VaR}$ is that it is not necessarily risk-sub-additive. This means that depending on the shape of the distribution and on the choice of $\alpha$, the $\mathrm{VaR}$ estimated for a portfolio can be larger than the sum of the $\mathrm{VaR}$ of its stand-alone components (see Embrechts, 2000, and Acerbi and TAsche, 2002). The VaR may therefore fail to recognize the benefits of diversification. The ES measures the average loss on a portfolio in the worst $\alpha \%$ cases. ACERBI and TASCHE (2002) show that the ES is risk sub-additive. The ES focuses on a segment of the distribution and not on a single point. It is therefore less sensitive than the VaR to the choice of $\alpha$. Since our study focuses on diversification, the sub-additivity of ES is a very desirable property. Another advantage of ES is that it includes extreme outcomes that are very relevant from a regulatory point of view, even if a bank may consider them as negligible because of its limited liability.

\section{Relationship between the Default Rate and the Economic Environment}

\subsection{Model Specification, Data and Estimation Method}

In this section, we develop two models of the evolution of the cantonal corporate default rates. The corporate default rate is defined as the numbers of defaults (Feuille officielle suisse) divided by the number of firms (Annuaire statistique fédéral) in a canton.

In the "macro model", we assume that the default rate in a canton is a function of its past value and of the current value of several national and cantonal macroeconomic variables. The first block of the macro model consists of $\mathrm{J}=22$ (for the number of cantons ${ }^{6}$ ) univariate autoregressions in which the national and cantonal macroeconomic variables enter as additional explanatory factors. We have

$$
\begin{aligned}
p_{j, t}= & \beta_{0, j}+\beta_{1} \cdot p_{j, t-1}+\beta_{2} \cdot \Delta I N C_{j, t} \\
& +\beta_{3} \cdot U R_{j, t}+\beta_{4} \cdot \Delta G D P_{t}+\beta_{5} \cdot i 3 m_{t}+\gamma_{j, t},
\end{aligned}
$$

6 The data for the six semi-cantons and for cantons Bern and Jura have been merged into four cantons. 
where $p_{j{ }^{\prime} t}$ is the default rate in canton $j, \Delta I N C_{j^{\prime} t}$ is the growth rate of real cantonal income, $U R_{j, t}$ is the cantonal unemployment rate, $\Delta G D P_{t}$ is the real GDP growth rate and $i 3 m_{t}$ is the 3-month Swiss franc LIBOR.

We expect real GDP growth and cantonal income growth to have a negative impact on the default rate, as a stronger economic activity or a stronger demand should improve the financial strength of firms. As argued in section 2, there is considerable empirical evidence that real economic activity is an important driver of credit risk. We expect the interest rate to have a positive impact on the default rate, as higher interest rates increase the burden of the debt for firms. Pesaran ET AL. (2006) also consider the interest rate as a credit risk driver. Finally, we expect the unemployment rate to have a positive impact on the default rate, since a high level of unemployment can depress the demand faced by local firms and thereby deteriorate their financial strength.

The macro model also assumes that the evolution of each macroeconomic variable is governed by a univariate autoregressive process of first order. The second block of the macroeconomic model is specified as follows:

$$
\begin{gathered}
\Delta I N C_{j, t}=\delta_{0, j}+\delta_{1} \cdot \Delta I N C_{j, t-1}+\omega_{j, t} \\
U R_{j, t}=\phi_{0, j}+\phi_{1} \cdot U R_{j, t-1}+\theta_{j, t} \\
\Delta G D P_{t}=\varphi_{0}+\varphi_{1} \cdot G D P_{t-1}+v_{t} \\
i 3 m_{t}=\lambda_{0}+\lambda_{1} \cdot i 3 m_{t-1}+\psi_{t}
\end{gathered}
$$

The macro model is very close in its architecture to Mc Kinsey's CreditPortfolioView (Wilson 1997a and 1997b). In particular, both models contain a first block explaining the evolution of the default rate as a function of different macroeconomic variables and a second block explaining the evolution of these macroeconomic variables based on autoregressive processes. Also, both models use the contemporaneous values of GDP growth, the employment rate and the interest rate as explanatory variables for the default rate. However, in WILsON (1997a and 1997b), the focus is on international diversification. Hence, all variables are observed at the national level. Another difference is that in WILSON (1997a and 1997b), the first block does not contain past values of the default rate as an explanatory variable. Of course, the need for including this explanatory variable depends on the degree of persistence of the default rate.

In the "one-factor autoregressive model", we simply assume that the current default rate is a function of its past value plus a constant. We have 


$$
p_{j, t}=\beta_{0, j}+\beta_{1} \cdot p_{j, t-1}+\gamma_{j, t}
$$

Because of its transparency, the one-factor autoregressive model serves as a useful point of comparison for the macroeconomic model. Another advantage is that the number of coefficients we have to estimate is small and that we do not need additional equations explaining the evolution of the macroeconomic variables.

Table 2 presents the summary statistics for the different variables. To save space, we base the statistics for the cantonal macroeconomic variables on the pool of the 22 cantons.

The cantonal default rates are observed at an annual frequency. As a result, we have only 22 observations per canton. We therefore combine the data of all cantons to form a pool, as in Wilson (1997a and 1997b). The pooled systems of equations defined by (1)-(1d) and by (2) are then estimated using "canton" specific fixed effects.

\subsection{Results}

The estimates of the macroeconomic model are presented in Table 3. For the default rates, the coefficient of the lagged dependant value is large and significant, indicating a high degree of persistence in the default rates. All macroeconomic variables have a statistically significant and economically plausible impact on the default rates.

The results of the one-factor autoregressive model are presented in Table 4. They also indicate a high degree of persistence in the evolution of the default rate. The comparison of the adjusted R-squared of the two models indicates that the inclusion of the macroeconomic variables leads to a modest increase in the explanatory power. 
Table 2: Summary Statistics for the Different Variables over the Period 1979-2000

\begin{tabular}{|c|c|c|c|c|c|}
\hline & Mean & Median & Maximum & Minimum & Std. Dev. \\
\hline$p_{Z H}$ & 2.04 & 1.92 & 2.85 & 1.49 & 0.40 \\
\hline$p_{B E / J U}$ & 1.63 & 1.41 & 2.67 & 0.88 & 0.57 \\
\hline$p_{L U}$ & 1.67 & 1.59 & 2.79 & 0.76 & 0.62 \\
\hline$p_{S Z}$ & 1.19 & 1.10 & 1.95 & 0.49 & 0.43 \\
\hline$p_{O W / N W}$ & 1.10 & 1.04 & 2.17 & 0.32 & 0.52 \\
\hline$p_{U R}$ & 0.75 & 0.61 & 1.60 & 0.00 & 0.48 \\
\hline$p_{G L}$ & 1.07 & 1.04 & 2.00 & 0.42 & 0.42 \\
\hline$p_{Z G}$ & 0.94 & 0.80 & 1.70 & 0.36 & 0.40 \\
\hline$p_{F R}$ & 1.43 & 1.23 & 2.50 & 0.57 & 0.66 \\
\hline$p_{S O}$ & 2.13 & 1.88 & 3.80 & 0.85 & 0.88 \\
\hline$p_{B S / B L}$ & 1.85 & 1.86 & 2.55 & 1.18 & 0.31 \\
\hline$p_{S H}$ & 1.93 & 1.85 & 3.68 & 0.96 & 0.71 \\
\hline$p_{A I / A R}$ & 1.21 & 1.11 & 2.31 & 0.39 & 0.55 \\
\hline$p_{S G}$ & 1.87 & 1.72 & 2.67 & 1.15 & 0.52 \\
\hline$p_{G R}$ & 0.82 & 0.72 & 1.27 & 0.40 & 0.30 \\
\hline$p_{A G}$ & 2.07 & 1.90 & 3.10 & 1.26 & 0.60 \\
\hline$p_{T G}$ & 1.71 & 1.28 & 3.36 & 0.68 & 0.95 \\
\hline$p_{T I}$ & 1.33 & 1.10 & 2.32 & 0.75 & 0.50 \\
\hline$p_{V D}$ & 2.71 & 2.35 & 4.10 & 1.76 & 0.82 \\
\hline$p_{V S}$ & 1.36 & 1.00 & 2.58 & 0.50 & 0.74 \\
\hline$p_{N E}$ & 2.36 & 1.86 & 3.72 & 1.47 & 0.81 \\
\hline$p_{G E}$ & 3.41 & 3.11 & 5.39 & 1.76 & 1.11 \\
\hline$\triangle I N C_{P O O L}$ & 2.16 & 2.25 & 15.93 & -10.85 & 2.96 \\
\hline$\triangle G D P$ & 1.64 & 1.60 & 4.38 & -1.44 & 1.64 \\
\hline$i 3 m$ & 4.37 & 4.00 & 9.19 & 1.31 & 2.46 \\
\hline$U R_{P O O L}$ & 1.86 & 1.14 & 7.80 & 0.00 & 1.90 \\
\hline
\end{tabular}

The data for the six semi-cantons and for cantons Bern and Jura have been merged to form four cantons. 
Table 3: Estimates Based on the Macroeconomic Model (1979-2002)

\begin{tabular}{|c|c|c|c|c|c|c|c|c|c|}
\hline \multirow{2}{*}{ 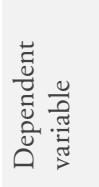 } & \multicolumn{2}{|c|}{$\begin{array}{l}\text { Range of fixed } \\
\text { effect }\end{array}$} & \multirow{2}{*}{ 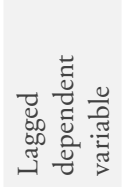 } & \multirow{2}{*}{$\sum_{z}^{j}$} & \multirow[b]{2}{*}{$s$} & \multirow[b]{2}{*}{ తి } & \multirow[b]{2}{*}{$\frac{2}{2}$} & \multirow{2}{*}{ 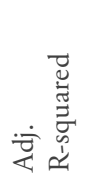 } & \multirow[b]{2}{*}{$\ddot{0}$} \\
\hline &.$\Xi$ & 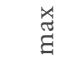 & & & & & & & \\
\hline$p_{j, t}$ & 0.001 & 0.006 & $\begin{array}{l}0.791^{* *} \\
(20.43)\end{array}$ & $\begin{array}{l}-1.19^{* *} \\
(-2.56)\end{array}$ & $\begin{array}{l}0.0412^{* *} \\
(2.51)\end{array}$ & $\begin{array}{l}-0.056^{* *} \\
(-6.68)\end{array}$ & $\begin{array}{l}0.035^{* *} \\
(5.55)\end{array}$ & 0.908 & 2.22 \\
\hline$\Delta I N C_{j, t}$ & 0.007 & 0.034 & $\begin{array}{l}0.124^{* *} \\
(2.45)\end{array}$ & & & & & 0.025 & 1.95 \\
\hline$U R_{j, t}$ & 0.010 & 0.005 & $\begin{array}{l}0.895^{* *} \\
(45.47)\end{array}$ & & & & & 0.854 & 0.98 \\
\hline$\Delta G D P_{t}$ & & & $\begin{array}{l}0.377^{* *} \\
(8.40)\end{array}$ & & & & & 0.137 & 1.56 \\
\hline$i 3 m_{t}$ & & & $\begin{array}{l}0.551^{* *} \\
(14.51)\end{array}$ & & & & & 0.325 & 1.67 \\
\hline
\end{tabular}

$\mathrm{t}$-values in parentheses, ${ }^{* *}$ significant at $1 \%$ level

Table 4: Estimates Based on the One-factor Autoregressive Model (1979-2002)

\begin{tabular}{llcccc}
\hline Dep. variable & \multicolumn{2}{c}{$\begin{array}{l}\text { Range of fixed effect } \\
\min \end{array}$} & $p_{j, t-1}$ & Adj. R-squared & D.W. \\
\hline$p_{j, t}$ & 0.126 & 0.479 & $\begin{array}{c}0.874^{* *} \\
(41.33)\end{array}$ & 0.840 & 1.95 \\
\hline
\end{tabular}

$\mathrm{t}$-values in parentheses, ${ }^{* *}$ significant at $1 \%$ level 


\section{Simulation of Default Rate Scenarios}

Based on the models' estimates of the previous section, we conduct a MonteCarlo simulation of economic scenarios and of the corresponding default rates. In the context of the macroeconomic model, the simulation of the default rate corresponding to economic scenario $n$, with $n=1$ to $N$, over a time horizon $T=3$ years involves the following steps:

- For each period $t$ in the time horizon $T$, we compute random shocks using a Cholesky decomposition of the variance-covariance matrix of the residuals of the system of equations defined by (1) to (1d);

- The random shocks are then entered into the pooled system of equations to compute the realizations of the macroeconomic variables and of the annual cantonal default rate corresponding to scenario $n$ for each period $t$ in the time horizon $T$;

- Based on the annual default rates, we compute the cumulative cantonal default rate over the time horizon $T$ corresponding to scenario $n$.

In the context of the one-factor autoregressive model, we go through the same steps using the pooled system of equations defined by (2).

\section{Loan Value Distribution and Portfolio Value Distributions}

To obtain the loan value distribution for each borrower, we simulate the status of each borrower (default/non default) and the related loan value at the end of the time horizon. This simulation is conditioned on the cumulative default rate corresponding to each economic scenario. A borrower will default at the end of the time horizon $T$ if his return on assets, drawn from the standard normal distribution, falls below a pre-specified threshold. This threshold is derived from the cumulative default rate corresponding to economic scenario $n$. When the scenario implies a high default rate, the threshold is high. The value of a defaulted loan is set to 50 . The value of non-defaulted loans is 100 plus an interest rate just compensating for the expected losses corresponding to the cantonal default rate averaged over the $N$ economic scenarios. For each borrower and for each economic scenario, $M$ individual scenarios are simulated. With $N=50$ and $M=100$, this leaves us with a distribution of $N \times M=5000$ loan-values for each borrower over horizon $T$.

The output of this stage can be visualized using a vector and matrix representation. The vector pcum $_{i, T}$ contains the $N$ cumulative default rate scenarios for 
a given canton over horizon $T$. The matrix loanvalue ${ }_{j, T}$ contains the $N \times M$ loan values for a given borrower conditioned on each default rate scenario. As $M$ tends to infinity, the frequency of the default values (50) in the first row of loanvalue ${ }_{j, T}$ tends to the cumulative default rate in the first row of pcum $_{j, T}$.

$$
\begin{aligned}
\operatorname{pcum}_{j, T} N \times 1 & =\left(\begin{array}{c}
7 \% \\
9 \% \\
10 \% \\
\ldots \\
7 \%
\end{array}\right) \\
\text { loanvalue }_{i, j, T} N \times M & =\left(\begin{array}{cccccc}
105 & 105 & 105 & \ldots & 105 \\
105 & 50 & 105 & \ldots & 105 \\
105 & 105 & 50 & \ldots & 105 \\
\ldots & \ldots & \ldots & \ldots & \ldots \\
105 & 105 & 105 & \ldots & 50
\end{array}\right)
\end{aligned}
$$

The value distribution for each cantonal portfolio is then obtained by aggregating the loan value distributions over all borrowers in a canton for each of the $N \times M$ scenarios.

Finally, the value distribution of the national portfolio is obtained by aggregating the value distributions of the cantonal portfolios.

\section{Calculation of the Credit Risk Diversification Potential}

Based on the portfolio value distributions, we calculate the $\mathrm{VaR}$ and the expected shortfall (both at the $1 \%$ level) for the national portfolio and for each cantonal portfolio. The national portfolio and each cantonal portfolio contain the same number of loans. The credit risk diversification potential is calculated by taking the difference between the average of the risks of the cantonal portfolios and the risk of the national portfolio.

Table 5 presents the results for a $100 \mathrm{CHF}$ portfolio with 500 loans. The results based on the macroeconomic model indicate that the risk of the national portfolio is $11 \%(\mathrm{VaR})$, respectively $12 \%$ (expected shortfall) smaller than the 
average of the risks of the cantonal portfolios. This reduction of risk is significant at the $1 \%$ level for the expected shortfall and at the $5 \%$ level for the VaR. The results based on the one-factor autoregressive model point at a slightly smaller risk reduction.

Table 5: Portfolio Risk and Risk Diversification Potential for a 3-year Horizon and 500 Loans (in CHF)

\begin{tabular}{lccccc}
\hline & \multicolumn{2}{c}{$\begin{array}{c}\text { Macroeconomic } \\
\text { model }\end{array}$} & \multicolumn{2}{c}{$\begin{array}{c}\text { One-factor autoregressive } \\
\text { model }\end{array}$} \\
& VaR & $\begin{array}{c}\text { Expected } \\
\text { shortfall }\end{array}$ & VaR & $\begin{array}{l}\text { Expected } \\
\text { shortfall }\end{array}$ \\
\hline $\begin{array}{l}\text { Average of the risks of the cantonal } \\
\text { portfolios }\end{array}$ & 1.998 & 2.243 & 1.980 & 2.227 \\
$\begin{array}{l}\text { Risk of the national portfolio } \\
\text { Risk diversification potential }\end{array}$ & 1.785 & 1.982 & 1.784 & 2.087 \\
\hline $\begin{array}{l}\text { Risk reduction in percent of the average } \\
\text { of the risks of the cantonal portfolios }\end{array}$ & $\begin{array}{c}10.6^{* * *} \\
(4.8)^{\mathrm{c}}\end{array}$ & $\begin{array}{c}11.7^{* *} \\
(3.1)^{\mathrm{c}}\end{array}$ & $\begin{array}{c}9.9^{*} \\
(5.6)^{\mathrm{c}}\end{array}$ & $\begin{array}{c}8.3^{* * *} \\
(3.1)^{\mathrm{c}}\end{array}$ \\
\hline
\end{tabular}

a Each cantonal portfolio includes 500 borrowers.

b For the national portfolio, we assume that the 500 borrowers are equally distributed across cantons.

c The values in parentheses are the standard errors based on bootstrapping.

$* * *,{ }^{* *}$ and ${ }^{*}$ indicate that the risk reduction is significant at the $1 \%, 5 \%$ and $10 \%$ level, respectively.

Table 6 presents the results for a portfolio with 2000 loans. The results based on the macroeconomic model indicate that the risk of the national portfolio is $20 \%$ $(\mathrm{VaR})$, respectively $21 \%$ (expected shortfall) smaller than the average of the risks of the cantonal portfolios. The risk reduction is significant at the $1 \%$ level for both indicators. The results based on the one-factor autoregressive model again point at a slightly larger risk reduction.

The comparison of the results between Tables 5 and 6 indicate that the risk reduction (expressed as a percentage of the average risk of the cantonal portfolio) is more substantial when the number of loans is large. This reflects the fact that with a larger number of loans, idiosyncratic risk (i.e., the risk that a borrower may default or not conditional on a cantonal default rate) decreases in importance compared to the risk related to fluctuations of the cantonal default rate. 
Table 6: Portfolio Risk and Risk Diversification Potential for a 3-year Horizon and 2000 Loans (in CHF)

\begin{tabular}{lcccc}
\hline & \multicolumn{2}{c}{$\begin{array}{c}\text { Macroeconomic } \\
\text { model }\end{array}$} & \multicolumn{2}{c}{$\begin{array}{c}\text { One-factor autoregressive } \\
\text { model }\end{array}$} \\
& VaR & $\begin{array}{c}\text { Expected } \\
\text { shortfall }\end{array}$ & VaR & $\begin{array}{c}\text { Expected } \\
\text { shortfall }\end{array}$ \\
\hline $\begin{array}{l}\text { Average of the risks of the cantonal } \\
\text { portfolios }\end{array}$ & 1.453 & 1.621 & 1.430 & 1.580 \\
Risk of the national portfolio & & & & \\
Risk diversification potential & 1.159 & 1.275 & 1.098 & 1.229 \\
\hline $\begin{array}{l}\text { Risk reduction in percent of the average } \\
\text { of the risks of the cantonal portfolios }\end{array}$ & $\begin{array}{c}20.2^{* * *} \\
(3.9)^{c}\end{array}$ & $\begin{array}{c}21.3^{* * *} \\
(2.6)^{c}\end{array}$ & $\begin{array}{c}23.2^{* * *} \\
(3.6)^{c}\end{array}$ & $\begin{array}{c}22.2^{* * *} \\
(2.7)^{c}\end{array}$ \\
\hline
\end{tabular}

a Each cantonal portfolio includes 2000 borrowers.

b For the national portfolio, we assume that the 2000 borrowers are equally distributed across cantons.

c The values in parentheses are the standard errors based on bootstrapping.

$* * *, * *$ and $*$ indicate that the risk reduction is significant at the $1 \%, 5 \%$ and $10 \%$ level, respectively.

Consequently, the possibility to diversify default rates across cantons becomes more important in relative terms.

So far, we have compared the risk of the national and cantonal portfolios assuming a fixed number of loans. This corresponds to a strategy where a bank diversifies its loan portfolio across cantons without expanding the size of its portfolio. But a bank could also expand the number of its loans in combination to national diversification. Figure 1 shows the expected shortfall of the portfolio for national diversification strategies based on a different number of loans, starting from a cantonal portfolio consisting of 500 loans. Spreading these 500 loans nationally brings a risk reduction of $12 \%$. Increasing the number of loans to 2000 and again diversifying them nationally brings a reduction of $45 \%$. Finally, increasing the number of loans to 11000 (22 cantons x 500 loans) and diversifying them nationally, would bring a risk reduction of $60 \%$. 
Figure 1: Expected Shortfall of the Loan Portfolio for Various Strategies

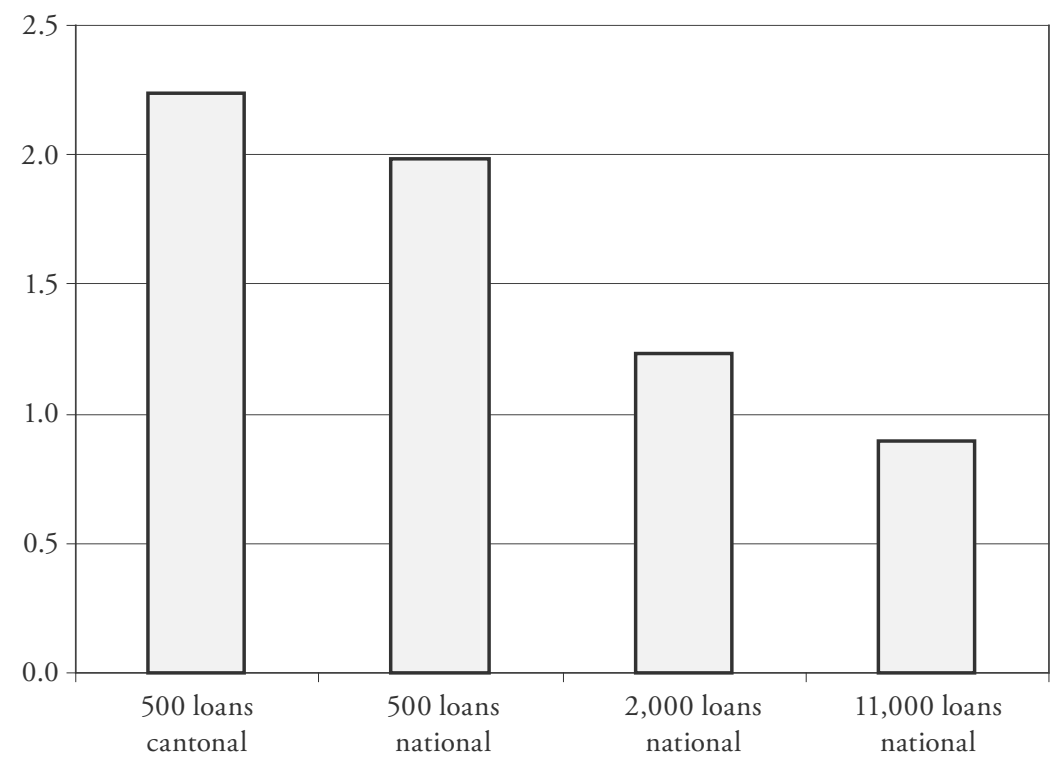

\section{A Plausibility Check Based on Provisioning}

To assess the plausibility of our results, we look at the volatility over time (standard deviation $)^{7}$ of the ratio of bank provisioning and amortizations to total loans. The volatility of provisioning is the only proxy for unexpected losses we can observe using bank data. By analogy with our approach based on the default rate, we estimate the credit risk diversification potential by taking the difference between (i) the average of the standard deviations of the provisioning rates calculated at the cantonal level and (ii) the standard deviation of the provisioning rate calculated at the national level. Note that by construction, the provisioning rate calculated at the national level includes a larger number of loans than the provisioning rate calculated at the cantonal level. As a result, the estimate of the credit risk diversification potential based on provisioning includes not only the effect of geographical diversification, but also the effect of having a larger number of loans - a bias that is not present in the approach based on the default rate.

7 The ratio itself is a measure of expected losses and cannot be used to assess diversification effects. 
The results are presented in Table 7. They cover the period 1987-2002, for which we have data at the individual bank level. We find that the risk diversification potential represents about $50 \%$ of the sum of the standard deviations of the provisioning rates calculated at the cantonal level. Besides the technical bias described above, another explanation for the larger estimate of the credit risk diversification potential is that the volatility of provisioning also reflects the possibility to diversify losses given default (due, for example, to the imperfect correlation of real estate prices across cantons).

Table 7: Risk Diversification Potential Based on Provisioning (in Percent of Total Loans)

\begin{tabular}{|c|c|}
\hline Standard deviation of provisioning calculated at the national level & 19.3 \\
\hline Average of the standard deviations of cantonal provisioning rates & 37.7 \\
\hline Risk diversification potential & 18.4 \\
\hline $\begin{array}{l}\text { Risk reduction in percent of the sum of the standard deviations } \\
\text { of cantonal provisioning rates }\end{array}$ & 48.8 \\
\hline
\end{tabular}

Regrettably, the very small number of nationally diversified Swiss banks prevents us to conduct a reliable cross section test of the relationship between the standard deviation of provisioning and the degree of national diversification of individual banks' loan portfolios. Indeed, only seven Swiss banks have allocated more than $20 \%$ of their loan portfolio outside the frontiers of their own canton.

\section{Conclusion}

This paper provides estimates of the reduction of credit risk that can be achieved in Switzerland by a national diversification of bank lending. We use a credit risk model based on corporate default rates observable at the cantonal (i.e., regional) level. Depending on the risk measure considered $-\mathrm{VaR}$ and expected shortfall we find that the risk of a national loan portfolio is about 10 to $20 \%$ smaller than the average of the risks of cantonal loan portfolios including the same number of loans. From a financial stability perspective, this substantial risk diversification potential should motivate particular scrutiny on those banks staying on the regional business model, such as the cantonal and regional banks. 
The methodology and results in this paper are subject to a number of limitations. First, because of the low frequency of the default rate data, the models explaining the evolution of the default rate must be estimated on a rather small number of observations. This implies a larger range of error in the estimation of the parameters and in the simulation of default rate scenarios. Second, our modelling of the evolution of the macroeconomic variables is quite basic. Third, because of the lack of data, we have to assume that within each canton, all firms can be characterized by the same - average - default probability and by the same recovery rate. In reality, default rates and recovery rates do of course differ depending on the borrower and the transaction. In spite of these caveats, our finding of a substantial credit risk diversification potential seems plausible and consistent with the evidence obtained from the volatility of bank provisioning at the national and at the cantonal levels.

\section{Literature}

Acerbi, C. and D. Tasche (2002), "On the Coherence of Expected Shortfall", Journal of Banking and Finance, 26 (7), pp. 1487-1503.

Acharya, Viral V., Iftekhar Hasan and Anthony Saunders (2002), "Should Banks Be Diversified? Evidence from Individual Bank Loan Portfolios", BIS Working Paper n o. 118.

Allen, Linda and Anthony Saunders (2004), "Incorporating Systemic Influences into Risk Measurements: A Survey of the Literature", Journal of Financial Services Research, 26, pp. 161-191.

Bangia, Anil, Francis X. Diebold, André Kronimus, Christian Schagen and Til Schuermann (2002), "Ratings Migration and the Business Cycle, With Applications to Credit Portfolio Stress Testing”, Journal of Banking and Finance, 26, pp. 235-264.

Carey, Mark (2002), "A Guide to Choosing Absolute Bank Capital Requirements", Journal of Banking and Finance, 26, p p. 929-951.

Crouhi, Michel, Dan Galai and Robert Mark (2000), "A Comparative Analysis of Current Credit Risk Models", Journal of Banking and Finance, 24, pp. 59-117.

Embrechts, Paul (2000), "Extreme value theory: Potential and Limitations as an Integrated Risk Management Tool”, Working Paper, ETH Zurich, Zurich.

Ervin, D.W. and T. Wilde (2001), "Procyclicality in the new Basel Accord", Risk, October. 
Hellwig, Martin (1998), “Allowing for Risk Choices in Diamond's Financial Intermediation as Delegated Monitoring", Discussion Paper no. 98-04, Sonderforschungsbereich 504, University of Mannheim, Mannheim.

Leyshon, Andrew and Nigel Thrift (1999), "Lists Come Alive: Electronic Systems of Knowledge and the Rise of Credit-Scoring in Retail Banking", Economy and Society, 28 (3), pp. 434-66.

Nickell, P., W. Perraudin and S. Varotto (2000), "Stability of Ratings Transitions", Journal of Banking and Finance, 24 (1/2).

Pesaran, M. Hashem, Til Schuermann, Björn-Jakob Treutler and Scott M. Weiner (2006), "Macroeconomic Dynamics and Credit Risk: A Global Perspective", Journal of Money, Credit, and Banking, 38 (5).

Swiss National Bank (2006), Die Banken in der Schweiz, Bern.

Saunders, Anthony (1999), Credit Risk Measurement, Wiley Frontiers in Finance, New York.

Wilson, Thomas (1997a), Portfolio Credit Risk (I), Risk, September 1997, pp. 111-117.

Wilson, Thomas (1997b), Portfolio Credit Risk (II), Risk, October 1997, pp. 56-61.

\section{SUMMARY}

This paper estimates the reduction of credit risk that can be achieved in Switzerland through a national diversification of bank lending. Using a credit risk model based on corporate default rates, we find that the risk of a nationally diversified loan portfolio can be up to $20 \%$ smaller than the average of the risks of cantonal portfolios. From a financial stability perspective, this substantial risk diversification potential should motivate particular scrutiny on the more than hundred Swiss banks staying on the regional business model. 